Revista Brasileira de Agricultura Irrigada v.6, $\mathrm{n}^{\circ} .2$, p. 151-163, 2012

ISSN 1982-7679 (On-line)

Fortaleza, CE, INOVAGRI - http://www.inovagri.org.br

DOI: $10.7127 /$ rbai.v6n200218

Protocolo 218 - 27/02/2012 Aprovado em 11/04/2012

\title{
USO DE ÁGUAS SALINAS E ADUBAÇÃO NITROGENADA NO CULTIVO DA MAMONEIRA BRS-ENERGIA
}

\author{
Allan N. Alves ${ }^{1}$, Hans R. Gheyi ${ }^{2}$, Claudio A. Uyeda ${ }^{3}$, Frederico A. L. Soares ${ }^{4}$, Reginaldo G. \\ Nobre $^{5}$, José A. F. Cardoso ${ }^{6}$
}

\section{RESUMO}

A potencialidade da mamoneira como combustível, criou uma perspectiva real para a expansão do seu cultivo em escala comercial, principalmente no semiárido nordestino. Assim sendo, objetivou-se com este estudo avaliar o crescimento inicial até 40 dias após a semeadurada mamoneira cultivar BRS Energia irrigada com águas de diferentes salinidades e adubação nitrogenada em condições de casa de vegetação pertencente ao Departamento de EngenhariaAgrícola do CTRN/UFCG, Campina Grande - PB. Usou-se o delineamento estatístico em blocos casualizados, sendo os tratamentos constituídos por diferentes níveis de condutividades elétricas da água de irrigação $\left(0,6 ; 1,6 ; 2,6 ; 3,6\right.$ e 4,6 dS m m $\left.^{-1}\right)$ e associados a diferentes doses de adubação nitrogenada $(50,75,100,125$ e $150 \%$ da dose indicada para ensaio em vaso), analisados em esquema fatorial 5 x 5, com 3 repetições.As variáveis analisadas foram: índice de velocidade de emergência, percentagem de emergência, altura de planta, número de folhas, área foliar e diâmetro de caule aos 40 dias após semeadura (DAS), e taxa de crescimento absoluto da altura de planta, entre 20 e 40 DAS. Os resultados obtidos permitem concluir que o aumento da salinidade influenciou negativamente todas variáveis estudadas, e que as doses de nitrogênio não influenciaram estas variáveis, com exceções ao índice de velocidade de emergência, e percentagem de emergência onde obteve-se efeito significativo na interação entre salinidade da água e adubação nitrogenada.

PALAVRAS-CHAVE: salinidade, crescimento inicial, Ricinus communis L..

\section{USE OF SALINE WATER AND NITROGEN IN CULTIVATION OF CASTOR BEAN BRS -ENERGY}

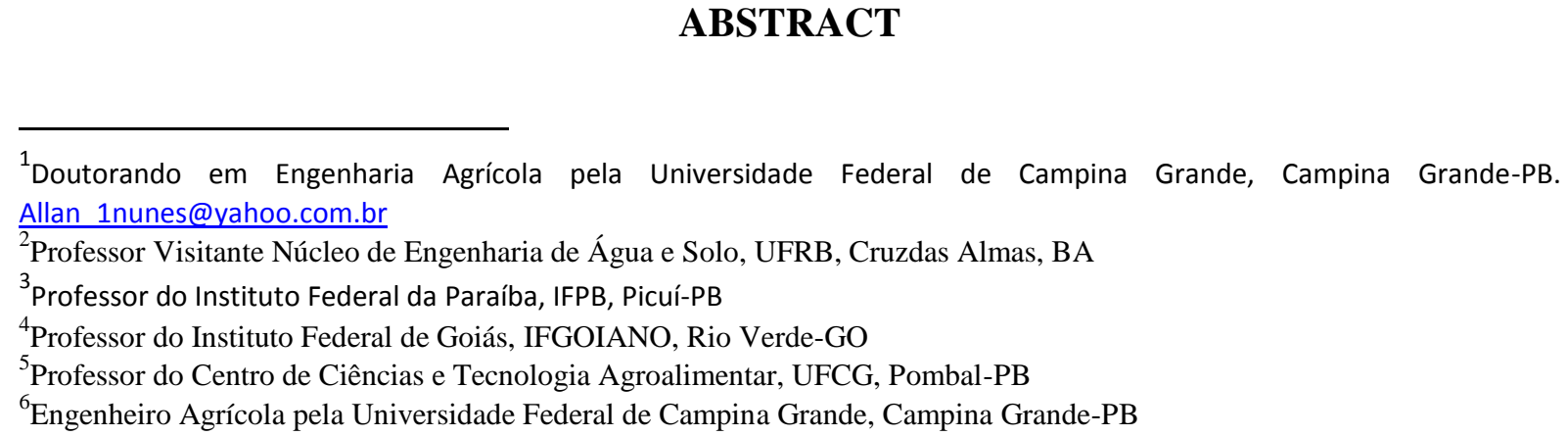




\section{USO DE ÁGUAS SALINAS E ADUBAÇÃO NITROGENADA NO CULTIVO DA MAMONEIRA BRS-ENERGIA}

The potentiality of castor bean as a fuel crop, has created a real prospect for the expansion of its cultivation on a commercial scale, especially in the semiarid northeast Brazil. Therefore, the aim of this study was to evaluate the initial growth of castor bean cultivar BRS Energy in the initial phase - up to 40 days after planting irrigated with waters of different salinities and nitrogen fertilization. The experiment was conducted under conditions of greenhouse of the Department of Agricultural Engineering of the CTRN / UFCG, Campina Grande - PB. A randomized block design was used, with treatments consisting of different levels of electrical conductivity of irrigation water $\left(0.6,1.6,2.6,3.6\right.$ and $\left.4.6 \mathrm{dS} \mathrm{m} \mathrm{m}^{-1}\right)$ associated with different doses of nitrogen $(50,75,100,125$ and $150 \%$ of the recommended dose for the pot experiments) in $5 \times 5$ factorial arrangement with three replications. The variables analysed were: index of velocity of emergence, percentage of emergence, plant height, number of leaves, leaf area and diameter at 40 days after sowing (DAS) and absolute growth rate of plant height, between 20 and 40 DAS. The results obtained permit to conclude that increase in water salinity negatively influenced all studied variables, and that the nitrogen did not influence these variables, except index of velocity of emergence and percentage of germination, where a significant interaction between salinity and nitrogen fertilization.was observed

KEY WORDS:salinity, initial growth, Ricinus communis L.

\section{INTRODUÇÃO}

$\mathrm{Na}$ região do semiárido brasileiro, a cultura da mamona (Ricinus communis L.) é uma das mais tradicionais e bastante cultivada por pequenos e médios produtores de quase todos os Estados da região. Seu cultivo também é uma tentativa de sustentabilidade e de inclusão social através da agricultura familiar, criando melhores condições de vida em regiões carentes (BELTRÃO et al., 2006).

Para crescer, desenvolver e produzir satisfatoriamente, a mamoneira necessita de suprimento hídrico diferenciado nas suas fases fenológicas e requer manejo compatível com sua capacidade de retirada de água na zona radicular, evitando desperdício de água e saturação do perfil do solo na área de cultivo; esses fatores evidenciam a necessidade de estudos sobre manejo da cultura, método de irrigação e qualidade de água da irrigação, o que pode implicar em redução ou aumento da produtividade para a cultura (BARRETO, 2004). A irrigação tornou-se um dos principais agentes de incorporação de áreas do semiárido nordestino no cenário da produção agrícola, assim como a utilização de águas salinas, que predominam nessa região em relação às águas de boa qualidade. Contudo sua utilização deve ser realizada obedecendo a certos critérios com intuito de evitar o acúmulo excessivo de sais no solo.Os efeitos dos sais sobre as plantas podem ser notados pela dificuldade de absorção de água, pela interferência destes nos processos fisiológicos, ou ainda por toxidez, influenciando diretamente no rendimento das plantas. (DIAS et al., 2003).

A adubação nitrogenada além de promover o crescimento das plantas, pode também reduzir os efeitos da salinidade nas plantas (FLORES et al., 2001).A explicação pode está relacionada às funções deste elemento nas plantas, uma vez que, desempenha função estrutural, fazendo parte de diversos compostos orgânicos vitais para o vegetal, como amino ácidos, proteínas, entre outros. Estudos têm demonstrado que o acúmulo desses solutos orgânicos eleva a capacidade de ajustamento osmótico das plantas à salinidade, e aumenta a resistência das culturas ao estresse hídrico e salino (LACERDA et al., 2003; SILVA et al., 2008). 


\section{USO DE ÁGUAS SALINAS E ADUBAÇÃO NITROGENADA NO CULTIVO DA MAMONEIRA BRS-ENERGIA}

A potencialidade produtiva da mamoneira, associada ao fácil cultivo e sua importância social e econômica, especialmente para a região Nordeste, requer estudos sobre seu cultivo irrigado com águas salinas. Neste sentido,

\section{MATERIAL E MÉTODOS}

$\mathrm{O}$ experimento foi desenvolvido sob condições de ambiente protegido (estufa agrícola), no Departamento de Engenharia Agrícola do Centro de Tecnologia e Recursos Naturais da Universidade Federal de Campina Grande, Campina Grande $\mathrm{PB}$, situada a $7^{\circ} 15^{\prime} 18^{\prime}$ ' S, e $35^{\circ} 52^{\prime} 28^{\prime}$ ' W e altitude média de $550 \mathrm{~m}$.

Adotou-se o delineamento experimental em blocos casualizados com três repetições, em esquema fatorial $5 \times 5$, sendo os tratamentos constituídos por diferentes níveis de condutividades elétricas da água de irrigação - CEa $(0,6$; objetivou-se com este trabalho avaliar o desempenho da cultivar de mamoneira BRS Energia irrigada com águas de diferentes salinidades e adubação nitrogenada na fase inicial de crescimento.

1,$6 ; 2,6 ; 3,6$ e 4,6 dS m$~^{-1}$ ) e associados a diferentes doses de adubação nitrogenada $(50 ; 75 ; 100 ; 125$ e $150 \%)$ sendo a dose de $100 \%$ (100 $\mathrm{mg} \mathrm{kg}^{-1}$ ) indicada para ensaio em vaso conforme Novais et al. (1991).

O material de solo foi coletado na profundidade de 0-30 $\mathrm{cm}$ de um Neosolo Regolítico Eutrófico,de textura francoarenosa, não salino e não sódico, devidamente destorroado e proveniente do Município de São José da Mata, PB, cujas características físicas e químicas (Tabela 1), foram obtidas conforme metodologias recomendadas pela Embrapa (1997).

Tabela 1. Características físicas e químicas do solo utilizado no experimento.

\begin{tabular}{ll}
\hline Características Físicas & Valor \\
\hline Granolumetria $(\boldsymbol{\%})$ & 73,4 \\
Areia & 16,8 \\
Silte & 9,8 \\
Argila & Franco arenoso \\
Classificação Textural & 1,42 \\
Densidade global $\left(\mathrm{kg} \mathrm{dm}^{-3}\right)$ & 49,47 \\
Porosidade $(\%)$ & \\
Complexo Sortivo $\left(\mathrm{cmol}_{\mathrm{c}} \mathrm{kg}^{-1}\right)$ & 1,88 \\
Cálcio & 3,13 \\
Magnésio & 1,64 \\
Sódio & 0,06 \\
Potássio & 4,72 \\
Extrato de Saturação & 0,66 \\
pHes & 1,62 \\
CE ${ }_{\mathrm{es}}\left(\mathrm{dS} \mathrm{m}^{-1}\right)$ & 3,13 \\
Cálcio $\left(\mathrm{mmol}_{\mathrm{c}} \mathrm{L}^{-1}\right)$ & 1,82 \\
Magnésio $\left(\mathrm{mmol}_{\mathrm{c}} \mathrm{L}^{-1}\right)$ & 0,74 \\
Sódio $\left(\mathrm{mmol}_{\mathrm{c}} \mathrm{L}^{-1}\right)$ & 2,0 \\
Potássio $\left(\mathrm{mmol}_{\mathrm{c}} \mathrm{L}^{-1}\right)$ & 0,0 \\
Cloreto $\left(\mathrm{mmol}_{\mathrm{c}} \mathrm{L}^{-1}\right)$ & 1,40 \\
Carbonato $\left(\mathrm{mmol}_{\mathrm{c}} \mathrm{L}^{-1}\right)$ & 19,67 \\
Bicarbonato $\left(\mathrm{mmol}_{\mathrm{c}} \mathrm{L}^{-1}\right)$ & \\
Percentagem de saturação $(\%)$ &
\end{tabular}


Para o cultivo das plantas foram utilizados vasos plásticos de aproximadamente $100 \mathrm{~L}$ de capacidade, preenchidos com $1 \mathrm{~kg}$ de brita ( $\mathrm{n}^{\mathbf{o}}$ zero) a qual cobria a base do vaso seguida $90 \mathrm{~kg}$ de solo o qual ocupava $2 / 3$ inferior do vaso e $30 \mathrm{~kg}$ de solo misturado com humos ( $2 \%$ do peso total de solo). Deixou-se $5 \mathrm{~cm}$ livres na superfície do vaso, para facilitar a irrigação. A drenagem foi acompanhada através de dois furos feitos na base dos vasos, sendo conectado um recipiente plástico para acompanhamento do volume drenado e consumido pela cultura.

Por ocasião do enchimento dos vasos, foi realizada a adubação mineral de plantio, onde para cada $\mathrm{kg}$ de material de solo foram aplicados, 300 e $150 \mathrm{mg}$ de $\mathrm{P}_{2} \mathrm{O}_{5}$ e $\mathrm{K}_{2} \mathrm{O}$, respectivamente; e para as doses de $\mathrm{N}$ foram aplicadas as respectivas proporções conforme tratamento, aplicando-se para cada $120 \mathrm{~kg}$ de solo (conteúdo de um vaso) $1 / 3$ da recomendação para o nitrogênio $(\mathrm{N})$ e o potássio $\left(\mathrm{K}_{2} \mathrm{O}\right)$, e a total de fósforo $(\mathrm{P})$. $\mathrm{O}$ restante (2/3) de $\mathrm{N}$ e $\mathrm{K}$ foi divido em cinco aplicações iguais aos 20, 30, 40, 50 e 60 dias após o semeadura (DAS), a fim de evitar acúmulo excessivo de sais.

Obtiveram-se os diferentes níveis de salinidade da água a partir da dissolução do cloreto de sódio $(\mathrm{NaCl})$ em água proveniente do sistema de abastecimento local, cuja quantidade (C) foi determinada com base na equação de Richards (1954), sendo $\mathrm{C}\left(\mathrm{mg} \mathrm{L}^{-1}\right)=640 \times \mathrm{CEa}\left(\mathrm{dS} \mathrm{m}{ }^{-1}\right)$, onde a CEa representa o valor desejado da condutividade elétrica da água. As respectivas águas eram acondicionadas em tonéis plásticos de $200 \mathrm{~L}$ de capacidade.

A cultivar utilizada no experimento foi a BRS-Energia, correspondente às selecionadas e recomendadas para ser cultivada na região Nordeste. Esta cultivar desenvolvida em rede pela Embrapa, EBDA e EMPARN e lançada em 2007, é uma cultivar precoce, com porte médio, em torno de $1,40 \mathrm{~m}$, ciclo entre 120 e 150 dias, caule verde com cera, cachos cônicos com tamanho médio de $60 \mathrm{~cm}$, frutos verdes com cera e indeiscentes. As sementes pesam entre 0,40 e $0,53 \mathrm{~g}$, rajadas com as cores marrom e bege, contendo $48 \%$ de óleo. A produtividade média experimental em condições de sequeiro é de $1.800 \mathrm{~kg} \mathrm{ha}^{-}$ ${ }^{1}$ (Milani, 2010).

As sementes foram cedidas pela Embrapa Algodão, passaram por criteriosa seleção, eliminando-se as defeituosas e aquelas com indício de fungos, ataque de insetos e danos mecânicos. $\mathrm{O}$ semeio foi realizado em 2 de outubro de 2010, com o solo em capacidade de campo; com o intuito de garantir plantas vigorosas, em cada vaso, foram semeadas 6 sementes a uma profundidade de $2 \mathrm{~cm}$ e distribuídas de forma equidistante. Aos 20 DAS, realizou-se o primeiro desbaste, deixandose apenas três plantas por vaso, as de melhor vigor. Aos 30 e 42 DAS foram realizados novos desbastes onde se eliminou em cada um, uma planta por vaso.

As lâminas aplicadas nas irrigações que eram realizadas diariamente ao final da tarde, tinham como base a necessidade hídrica das plantas balizadas em função do balanço hídrico: volume aplicado menos o volume drenado que foi acrescido de uma fração de lixiviação em média de $10 \%$ para evitar acúmulo de sais no solo.

$\mathrm{O}$ crescimento inicial da mamoneira BRS Energia foi avaliado através das variáveis, índice de velocidade de emergência (IVE) e percentagem de emergência (PE) até o vigésimo dia, altura de planta (AP), número de folhas (NF), área foliar (AF) e diâmetro de caule (DC) aos 40 DAS, e taxa de crescimento absoluto da altura de planta (TCAap), entre 20 e 40 DAS seguindo-se metodologia de Benincasa (2003).

$O$ índice de velocidade de emergência (IVE) foi determinado registrando-se diariamente o número de sementes germinadas e calculado pela 


\section{USO DE ÁGUAS SALINAS E ADUBAÇÃO NITROGENADA NO CULTIVO DA MAMONEIRA BRS-ENERGIA}

fórmula proposta por Maguire (1962). Foram consideradas como emergidas as plântulas que apresentavam os cotilédones totalmente livres. A percentagem de emergência foi calculada de acordo com Labouriau \&Valadares (1976).

\section{RESULTADOS E DISCUSSÃO}

Os níveis de salinidade afetaram significativamente $(\mathrm{p}<0,01)$ todas as variáveis estudadas. Para o fator dose de nitrogênio não houve efeito significativo
Os resultados obtidos foram submetidos à análise davariância pelo teste 'F'ao nível de 0,05 e 0,01 de probabilidade e nos casos de significância, realizou-se análise de regressão polinomial utilizandose o software SISVAR (FERREIRA, 2003).

para nenhuma das variáveis estudadas, enquanto a interação salinidade $\mathrm{x}$ nitrogenio foi significativa ao nível de 0,05 de probabilidade, apenas para a IVEe PE (Tabela 2).

Tabela 2.Resumo de teste $\mathrm{F}$ para índice de velocidade de emergência (IVE), percentagem de emergência (PE), altura de planta (AP), número de folhas (NF), diâmetro de caule (DC) e área foliar (AF) aos 40 dias após semeadura (DAS) e taxa de crescimento absoluto de altura de planta (TCAap) entre 20-40 (DAS) da mamoneira em função de diferentes níveis de salinidade da água de irrigação e doses de nitrogênio

\begin{tabular}{|c|c|c|c|c|c|c|c|}
\hline & \multicolumn{7}{|c|}{ Teste F } \\
\hline Fonte de variação & IVE & $\begin{array}{c}\mathrm{PE} \\
\%\end{array}$ & $\begin{array}{c}\text { AP } \\
(\mathrm{cm})\end{array}$ & $\mathrm{NF}$ & $\begin{array}{c}\mathrm{DC} \\
(\mathrm{mm})\end{array}$ & $\begin{array}{l}\mathrm{AF} \\
\left(\mathrm{m}^{2}\right)\end{array}$ & $\begin{array}{c}\text { TCAap } \\
\left(\mathrm{cm} \mathrm{dia}^{-1}\right)\end{array}$ \\
\hline Salinidade da água $(\mathrm{S})$ & $* *$ & $* *$ & $* *$ & $* *$ & $* *$ & $* *$ & $* *$ \\
\hline Reg. Linear & $* *$ & $* *$ & $* *$ & $* *$ & $* *$ & $* *$ & $* *$ \\
\hline Reg. Quadrática & $*$ & $* *$ & $\mathrm{~ns}$ & $\mathrm{~ns}$ & $\mathrm{~ns}$ & $\mathrm{~ns}$ & ns \\
\hline $\begin{array}{l}\text { Doses nitrogênio (N) } \\
\text { Reg. Linear } \\
\text { Reg. Quadrática }\end{array}$ & ns & ns & ns & ns & ns & ns & ns \\
\hline Interação (S x N) & $*$ & $*$ & $\mathrm{~ns}$ & $\mathrm{~ns}$ & $\mathrm{~ns}$ & $\mathrm{~ns}$ & ns \\
\hline Bloco & ns & ns & ns & ns & ns & ns & ns \\
\hline $\mathrm{CV}(\%)$ & 22,44 & 20,19 & 17,52 & 29,41 & 14,15 & 37,55 & 22,44 \\
\hline
\end{tabular}

Constatou-se que a salinidade da água de irrigação exerceu influencia significativa sobre a variável IVE ao nível de 0,05 de probabilidade (Tabela 2). De acordo com o desdobramento da interação, verifica-se que só houve diferença significativa entre as diferentes doses de nitrogênio ao se irrigar com uma água de $\mathrm{CE}$ de 4,6 dS $\mathrm{m}^{-1}$ (Figura 1A), apresentando, a cada incremento unitário da dose de nitrogênio, uma redução de 0,0018 emergência dia $^{-1}$, por outro lado, observando o desdobramento da salinidade da água de irrigação (CEa) dentro de cada nível da dose de nitrogênio, verifica-se que houve efeito significativo no IVE devido a salinidade da água de irrigação para todas as doses de nitrogênio utilizadas no experimento (Figura 1B). Nota-se um decréscimo no IVE, segundo as equações de regressão, de 9,09, 9,06, 11,11 e $13,17 \%$ por aumento unitário na condutividade elétrica da água de irrigação para a dose de 50, 75, 100 e $125 \%$ de $\mathrm{N}$, respectivamente; enquanto para a dose de $150 \%$ de $\mathrm{N}$ a CEa de $1,79 \mathrm{dS} \mathrm{m}^{-1}$ proporcionou o maior IVE $(0,50$ plântulas emergidas $\mathrm{dia}^{-1}$ ). 


\section{USO DE ÁGUAS SALINAS E ADUBAÇÃO NITROGENADA NO CULTIVO DA MAMONEIRA BRS-ENERGIA}

Com relação à $\mathrm{PE}$, conforme $\mathrm{o}$ desdobramento da interação, foi observado que ao se irrigar as plantas com água de condutividade elétrica de $4,6 \mathrm{dS} \mathrm{m}^{-1}$ houve efeito significativo na dose de $150 \%$ de nitrogênio utilizada, demonstrado pela redução da $\mathrm{PE}$ de $0,38 \%$ com o aumento unitário da dose de nitrogênio (Figura 1C). Já ao respeito do desdobramento da salinidade da água de irrigação (CEa) dentro de cada nível da dose de nitrogênio, assim como verificado para o IVE; observou-se que todas as doses de nitrogênio estudadas apresentaram efeito significativo em função do aumento da salinidade da água de irrigação (Figura 1D). De acordo com as equações lineares de regressão, constatou-se que a redução da PE por aumento unitário da salinidade da água de irrigação para as doses 50, 75 e $100 \%$ foi $6,11,6,45$ e $7,51 \%$, respectivamente, enquanto para as doses de 125 e $150 \%$ de $\mathrm{N}$ onde o modelo que melhor se ajustou foi 0 quadrático,verificou-se redução, respectivamente, de 51,54 e38,05\%, em tratamento de CEa de 4,6 dS m ${ }^{-1}$ em

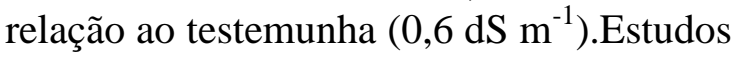
realizados por Silva et al. (2005) envolvendo o crescimento inicial de duas cultivares de mamoneira cultivadas sob estresse salino, contribuem com os resultados encontrados neste trabalho, ao constatarem que o IVE sofreu efeito antagônico da CEa com decréscimos em seus valores com o aumento da salinidade da água de irrigação. A redução da $\mathrm{PE}$ assim como do IVE pode está relacionado à diminuição do potencial osmótico, pois sabe-se que a salinidade, ao reduzir o potencial osmótico do meio, aumenta o tempo de embebição de água pelas sementes, resultando, inicialmente, em prolongamento do período de emergência da plântula (PIZARRO, 1985); uma menor absorção de água pelas sementes afeta a percentagem de germinação (MENGUEL \& KIRKBY, 1987; RHOADES \& LOVEDAY, 1990).

Pôde-se observar que o modelo que melhor descreve o comportamento das plantas para a variável AP foi o linear, onde, de acordo com a equação (Figura 2A), o aumento da salinidade da água de irrigação foi inversamente proporcional à altura de planta; gerando um decréscimo na AP por incremento unitário da CEa de aproximadamente $9,68 \%$, ou seja, 


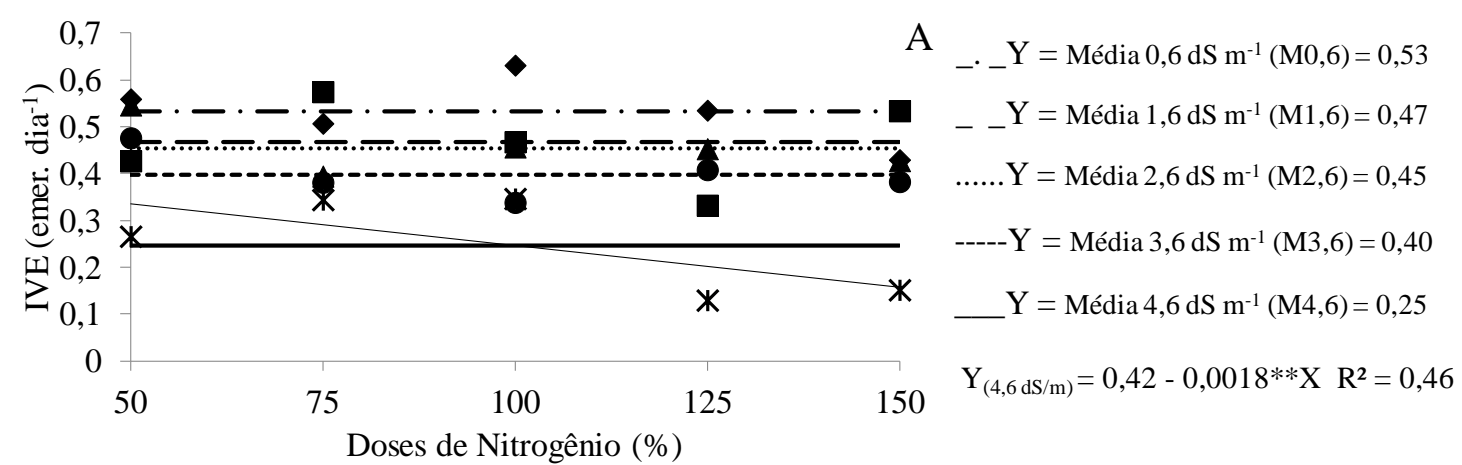

$\bullet 0,6 \mathrm{dS} / \mathrm{m} \bullet 1,6 \mathrm{dS} / \mathrm{m} \Delta 2,6 \mathrm{dS} / \mathrm{m} \bullet 3,6 \mathrm{dS} / \mathrm{m} * 4,6 \mathrm{dS} / \mathrm{m}$
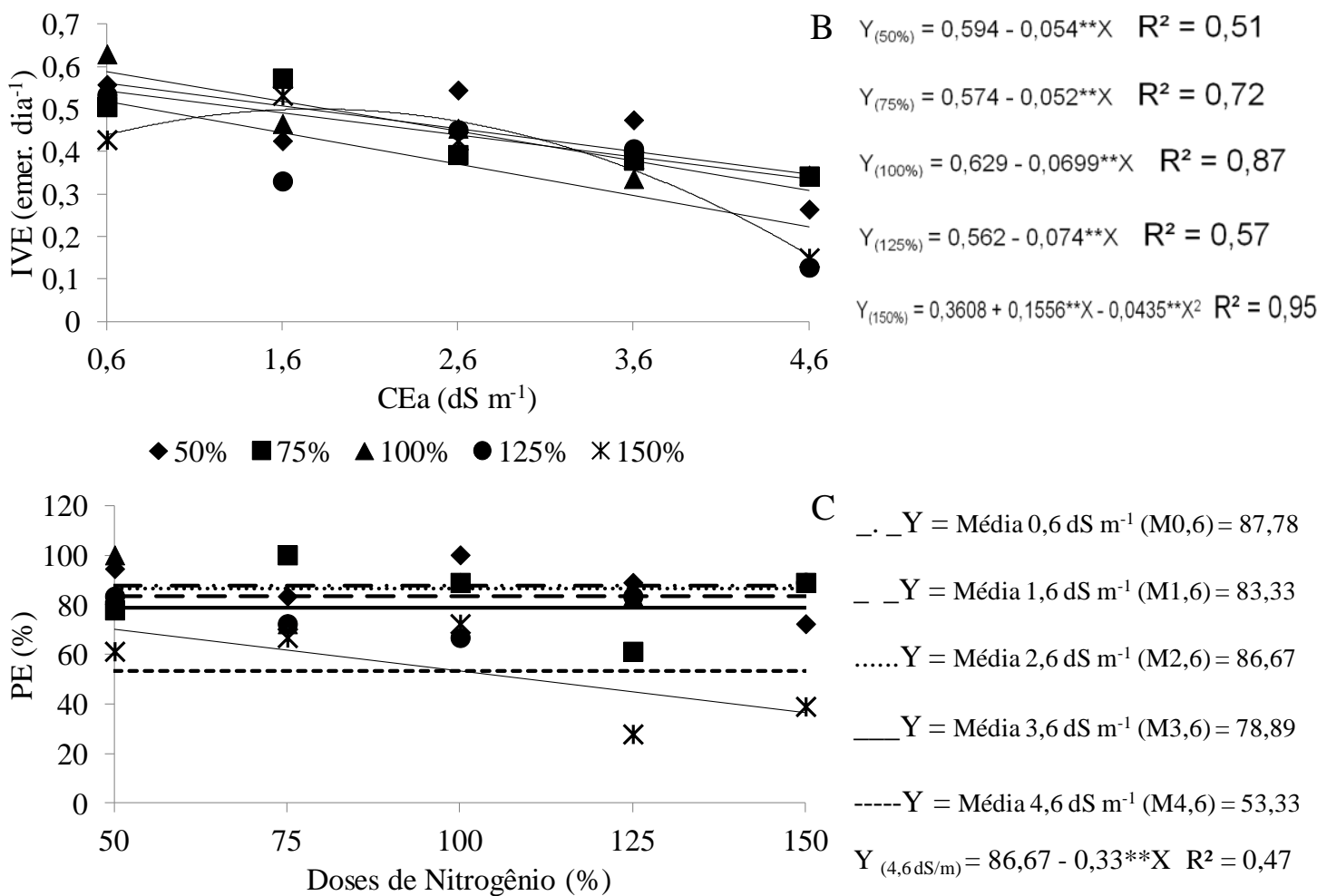

$\bullet 0,6 \mathrm{dS} / \mathrm{m} \bullet 1,6 \mathrm{dS} / \mathrm{m} \Delta 2,6 \mathrm{dS} / \mathrm{m} \bullet 3,6 \mathrm{dS} / \mathrm{m} * 4,6 \mathrm{dS} / \mathrm{m}$

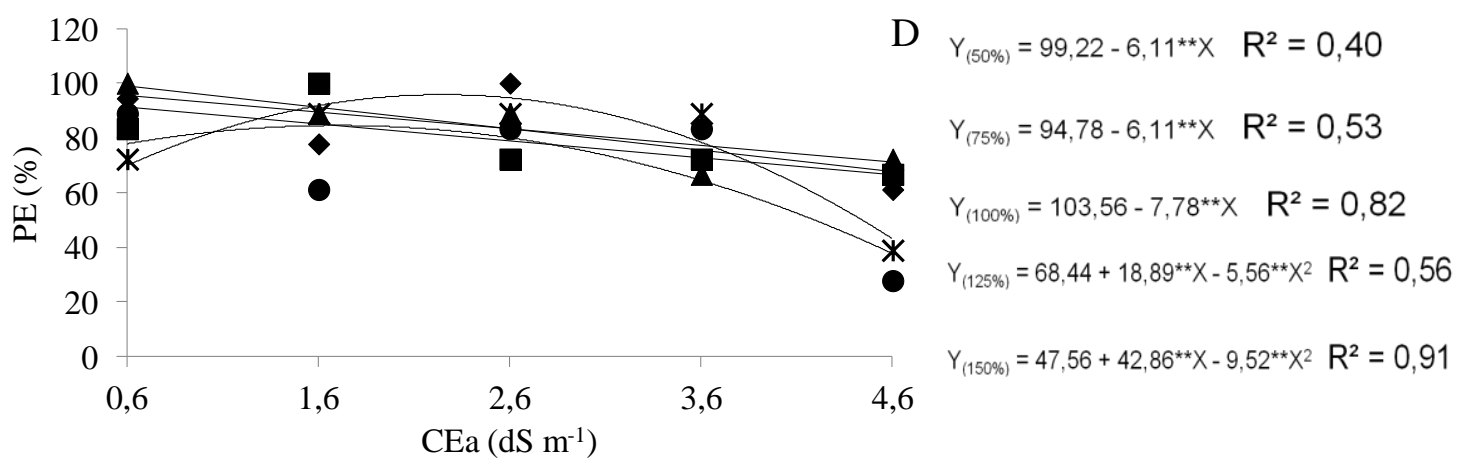

$\bullet 50 \% \quad 75 \% \quad \Delta 100 \% \bullet 125 \% \quad * 150 \%$

Figura 1 - Desdobramento do índice de velocidade de emergencia (IVE) e porcentagem de emergencia(PE) para as doses de nitrogênio dentro de salinidade da água(CEa) (A e C) e da $\mathrm{CEa}$ dentro de cada nível de nitrogenio (B e D) 


\section{USO DE ÁGUAS SALINAS E ADUBAÇÃO NITROGENADA NO CULTIVO DA MAMONEIRA BRS-ENERGIA}

correspondendo a uma redução de $38,76 \%$ na AP das plantas irrigadas com $\mathrm{CEa}$ de $4,6 \mathrm{dS} \mathrm{m}^{-1}$ em relação às plantas irrigadas com água de $0,6 \mathrm{dS} \mathrm{m}^{-1}$ (testemunha). Silva et al. (2008) em trabalho com as cultivares Paraguaçu e BRS- Energia, sob diferentes níveis de salinidade da água de irrigação, verificaram, aos 80 DAS, decréscimos relativos entre os níveis 0,7 e $4,7 \mathrm{dS} \mathrm{m}^{-1}$, de 62,45\%; corroborando com os resultados encontrados neste estudo, pois, muito embora os dados expostos do presente trabalho sejam referentes aos 40 DAS, o comportamento da variável indica que a mamoneira BRS-Energia tem seu crescimento afetado pelo aumento da salinidade da água de irrigação, fato este também observado por Lima et al. (2011a), em estudo com essa mesma cultivar e

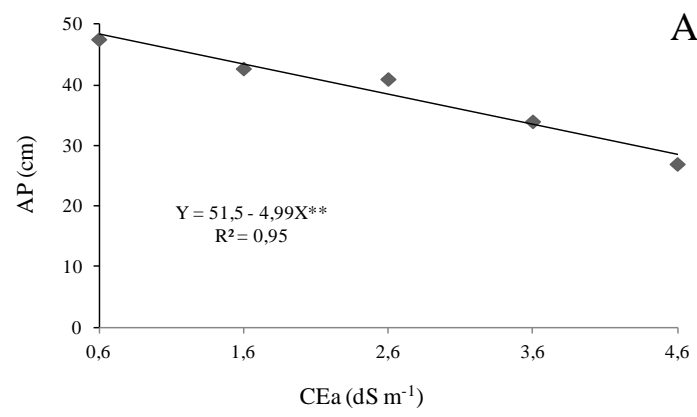

níveis de CE da água de irrigação de 0,4 a $4,4 \mathrm{dS} \mathrm{m}^{-1}$, verificando uma redução na altura de plantas de $26,9 \%$ entre os níveis 0,4 e $4,4 \mathrm{dS} \mathrm{m}^{-1}$ aos 21 DAS. Esse efeito inibitório do crescimento das plantas pode ser explicado pela diminuição do potencial osmótico alterando o $\mathrm{pH}$, alterando o balanço nutricional e desestruturando agregados do solo; pela toxicidade iônica, desequilíbrio nutricional ou ambos, em função do acúmulo de determinados sais nos tecidos vegetais (FLOWER, 2004), como também pelo aumento da pressão osmótica, atuando de forma negativa nos processos fisiológicos, reduzindo a absorção de água pelas raízes, inibindo a atividade meristemática e o alongamento celular, resultando em menor crescimento das plantas (AYERS \& WESTCOT, 1999).

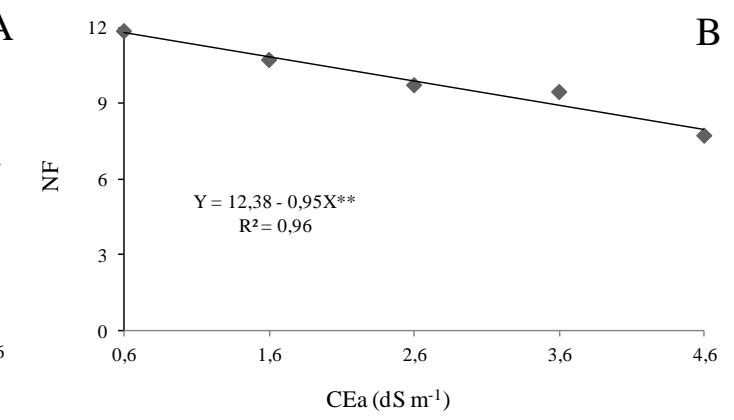

Figura 2 - Altura de planta (AP) (A) e número de folhas (NF) da mamoneira, em função da condutividade elétrica da água de irrigação - $\mathrm{CEa}$, aos 40 dias após a semeadura.

Para a variável número de folhas verificou-se efeito significativo ao nível de 0,01 de probabilidade para a salinidade da água (Tabela 2). O estudo de regressão para NF apresentou efeito linear decrescente, sendo o menor número 8 folhas obtido no tratamento com $\mathrm{CEa}$ de $4,6 \mathrm{dS} \mathrm{m}^{-1}$ (Figura 2B). Observou-se uma diminuição no NF de $7,67 \%$ por aumento unitaria da CEa. Resultados encontrados em outros estudos comprovam o efeito deletério da salinidade da água de irrigação na cultura da mamoneira como os encontrados por Cavalcanti et al. (2005), estudando em condição de ambiente protegido, a influência da salinidade da água de irrigação na germinação e crescimento da BRS-
Nordestina, verificaram redução no NF a partir de $1,7 \mathrm{dS} \mathrm{m}^{-1}$ de $2,95 \%$ por aumento unitário da CEa; Silva et al. (2008), verificaram que, a salinidade da água de irrigação promoveu progressiva redução no NF com decréscimos por aumento unitário da CEa de 7,5\% para a cultivar BRS Energia aos 80 DAS.

Através da análise de regressão (Figura 3A), observou-se para a variável DC, assim como as variáveis já citadas, redução de seus valores na medida em que aumentou a $\mathrm{CEa}$, constatando-se decréscimos entre testemunha e nível mais alta de salinidade estudado $\left(4,6 \mathrm{dS} \mathrm{m}^{-1}\right)$, de aproximadamente $26,12 \%$ para o DC. O aumento da salinidade da água de irrigação proporcionou efeito 


\section{USO DE ÁGUAS SALINAS E ADUBAÇÃO NITROGENADA NO CULTIVO DA MAMONEIRA BRS-ENERGIA}

linear e decrescente para esta variável, havendo decréscimo no DC de $6,53 \%$ por aumento unitário da CEa. A diminuição do DC foi observado por Lima et al. (2008) e Silva et al. (2008), demonstrando que a salinidade da água de irrigação afeta todas as variáveis, impedindo que a planta tenha condições de se desenvolver de forma satisfatória para se obter um bom aporte. É comum haver diferenças dos efeitos salinos nas espécies vegetais, entre genótipos de uma mesma espécie e estádios de desenvolvimento de um mesmo genótipo (TAIZ \& ZEIGER, 2009). Para Ayers \& Westcot (1999), a redução do potencial osmótico do substrato atua de forma negativa sobre os processos fisiológicos,

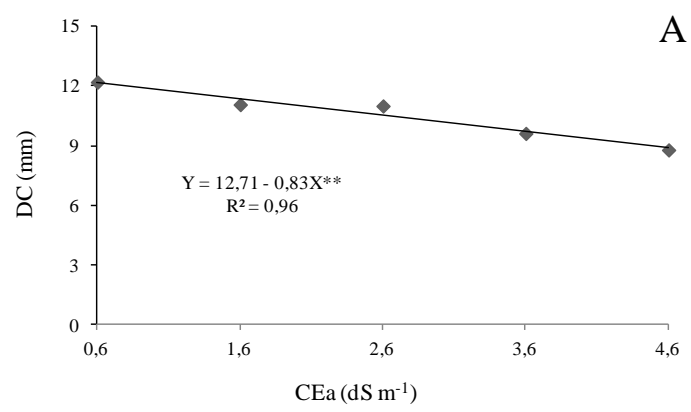

reduzindo a absorção de água pelas raízes, inibindo a atividade meristemática e o alongamento celular, advindo, como consequência, a redução no crescimento das culturas.

Analisando a variável área foliar, observou-se que o fator salinidade da água de irrigação, afetou significativamente esta variável ao nível de 0,01 (Tabela 2). Constatou-se também que o modelo que se ajustou ao comportamento desta variável foi o linear. De acordo com a equação de regressão (Figura 3B), nota-se que a área foliar sofreu progressivas reduções a partir do primeiro nível de salinidade $\left(0,6 \mathrm{dS} \mathrm{m}^{-}\right.$ $\left.{ }^{1}\right)$.

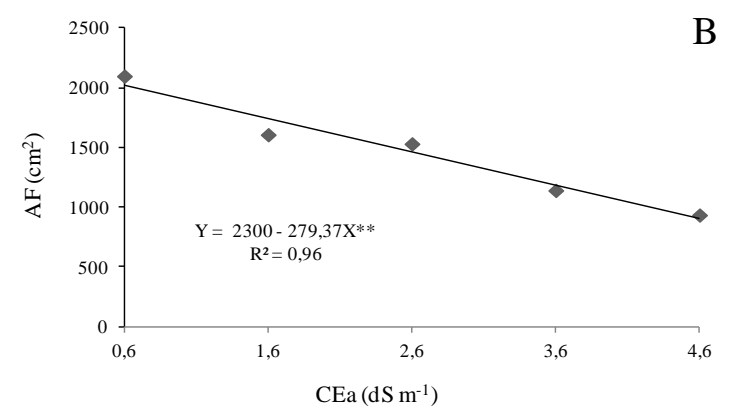

Figura 3 - Diâmetro de caule (DC) (A) e área foliar (AF) (B), da mamoneira, em função da condutividade elétrica da água de irrigação $(\mathrm{CEa})$, aos 40 dias após a semeadura.

O decréscimo na área foliar por aumento unitário da CEa foi de 12,15\% gerando uma diferença percentual entre os níveis salinos minimo e maximo estudados de $48,6 \%$. Os resultados encontrados neste trabalho harmonizam-se com os encontrados por Lima et al. (2011b) que em estudos sobre a influencia do estresse salino no crescimento da cultivar BRS Energia, constataram que a área foliar aos 21 DAS decresceu com o aumento da $\mathrm{CEa}$; Silva et al. (2008) observaram diminuição significativa da área foliar da cultivar BRS Energia com decréscimos relativos por aumento unitário da CEa de $14,6 \%$ aos 80 DAS.

A redução da área foliar é um importante mecanismo adaptativo de plantas cultivadas sob estresse salino, de forma que nessas condições,é interessante a redução na transpiração e, consequentemente, diminuição do carregamento de íons de $\mathrm{Na}^{+}$e $\mathrm{Cl}^{-}$no xilema e conservação da água nos tecidos das plantas (TAIZ \& ZEIGER,2009). Este decréscimo da área foliar está relacionado a um dos mecanismos de adaptação da planta ao estresse salino, diminuindo a superfície transpirante (TESTER \& DAVENPORT, 2003).

Estudos realizados com outras culturas têm evidenciado efeito adverso do estresse salino, provocando redução da área foliar com o incremento do nível salino, como os trabalhos realizados com a cultura do pinhão manso (SOUSA et al., 2011), do amendoim (CORREIA et al., 


\section{USO DE ÁGUAS SALINAS E ADUBAÇÃO NITROGENADA NO CULTIVO DA MAMONEIRA BRS-ENERGIA}

2009) e meloeiro (Medeiros et al., 2007), entre outras culturas de importância agronômica.

Através da análise estatística observou-se efeito significativo dos níveis de salinidade da água de irrigação sobre a taxa de crescimento absoluto em altura de planta, ao nível de 0,01 de probabilidade, pelo teste F, no período entre 20 e 40 DAS (Tabela 2). Com base na equação de regressão apresentada na Figura 4, constatou-se que a diferença na TCAap entre o primeiro nível $\left(0,6 \mathrm{dS} \mathrm{m}^{-1}\right)$ e o ultimo nível salino $\left(4,6 \mathrm{dS} \mathrm{m}^{-1}\right)$ foi de $37,28 \%$; ainda segundo a equação de regressão ocorreu redução de $9,32 \%$ da TCAap por incremento unitário da CEa. Os resultados obtidos por Lima et al. (2011b), em estudo com essa mesma cultivar e níveis de CE da água de irrigação de 0,4 a $4,4 \mathrm{dS} \mathrm{m}^{-1}$, ressaltaram redução de $3,11 \%$ por incremento unitário da CEa, ou seja, decréscimos de $12,45 \%$ das plantas irrigadas com CEa de 4,4 dS $\mathrm{m}^{-1}$ em relação as sob CEa de $0,4 \mathrm{dS} \mathrm{m}^{-1}$.A taxa de crescimento de plantas é geneticamente controlada, de maneira que fatores que determinem diferentes taxas iniciais de crescimento terão efeito apenas durante a fase de crescimento exponencial das plantas, diminuindo de intensidade à medida que as plantas se desenvolvem (CARVALHO \& NAKAGAWA, 2000). Nery et al. (2007) em estudo com pinhão manso sob condições de estresse salino, verificaram que a taxa de crescimento absoluto em altura foi reduzida linearmente com o incremento da CEa, corroborando com os resultados encontrados nesse estudo, contribuindo para a justificativa desta diminuição da TCA, haja vista, que o processo de crescimento é particularmente sensível ao efeito dos sais, de forma que a taxa de crescimento pode servir de critério para avaliar o grau de estresse e a capacidade da planta de superá-lo (LARCHER, 2004). Mesmo espécies consideradas tolerantes ao sal apresentam redução do crescimento em presença de salinidade, embora em igual concentração de sal, plantas tolerantes sejam capazes de manter maiores taxas de crescimento em relação às sensíveis (NEUMANN, 1997).

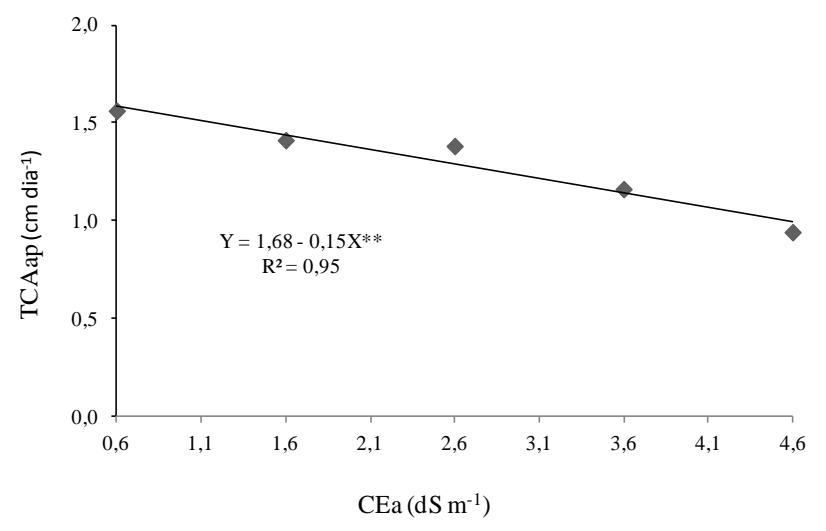

Figura 4 - Taxa de crescimento absoluto de altura de planta (TCAap) da mamoneira, em função da condutividade elétrica da água de irrigação - CEa, entre 20 e 40 dias após a semeadura.

\section{CONCLUSÕES}

A cultivar BRS Energia apresentouse sensível à presença de sais na água de irrigação com influência significativa observada desde a emergência das plantas.
A adubação nitrogenada não se mostrou eficaz na diminuição dos efeitos da salinidade sobre o crescimento inicial das plantas. 
As variáveis de crescimento índice de velocidade de emergência, percentagem de emergência, altura de planta, número de folhas, diâmetro de caule, área foliar taxa de crescimento absoluto de altura de

\section{REFERÊNCIAS}

AYERS, R. S.; WESTCOT, D. W. (trad.) A qualidade da água na agricultura. Campina Grande: UFPB, 1999. 218p. (Estudos FAO. Irrigação e Drenagem, 29).

BARRETO, A. N. Quantificação de água necessária para a mamoneira irrigada com base nas constantes hídricas do solo. In: Congresso Nacional da Mamona, 1, 2004, Campina Grande. Anais...Campina Grande: EMBRAPA, 2004. CD-Rom.

BELTRÃO, N. E. de M.; CARTAXO, W. V.; PEREIRA, S. R. P.; SOARES, J. J.; SILVA, O. R. R. F. O cultivo sustentável da mamona no semiárido brasileiro. Campina Grande: 2006. 62p. (Embrapa Algodão, CARTILHA, 1).

BENINCASA, M. M. P. Análise de crescimento de plantas. Jaboticabal, FUNEP, 2003. 41p.

CARVALHO, N. M.; NAKAGAWA, J. Sementes: ciência, tecnologia e produção. 4. ed. Jaboticabal: FUNEP, 2000, 588p.

CAVALCANTI, M. L. F., FERNANDES, P. D., GHEYI, H. R., BARROS JÚNIOR, G., SOARES, F. A. L., SIQUEIRA, E. C. Tolerância da mamoneira BRS 149 à salinidade: germinação e características de crescimento. Revista Brasileira de Engenharia Agrícola e Ambiental,v.9, (Suplemento), p.57-61, 2005.

CORREIA, K. G.; FERNANDES, P. D.; GHEYI, H. R.; NOBRE, R. G.; SANTOS, T. S. Crescimento produção e fluorescência da clorofila a em amendoim planta, apresentaram diminuição com o aumento da salinidade da água de irrigação, onde a variável área foliar se mostrou mais sensível ao efeito adverso do estresse salino.

sob condições de salinidade. Revista Ciência Agronômica,v. 40, n. 4, p. 514521, 2009.

DIAS, N. S.; GHEYI, H. R.; DUARTE, S.N. Prevenção, manejo e recuperação dos solos afetados por sais. Piracicaba: ESALQ, Departamento de Engenharia Rural, 2003. 118p. Série Didática, 13.

EMPRESA BRASILEIRA DE PESQUISA AGROPECUÁRIA BRASILEIRA EMBRAPA. Manual e métodos de análise do solo. 2.ed. Rio de Janeiro, Centro Nacional de Pesquisa de solos, 1997. 212p. FERREIRA, D. F. SISVAR 4,6 - programa de análise estatística. Lavras: Universidade Federal de Lavras, 2003. 1 CD-ROM.

FLORES, P.; CARVAJAL, M.; CERDA, A.; MARTINEZ, V. Salinity and ammonium/nitrate interactions on tomato plant development, nutrition, and metabolites.Journal of Plant Nutrition, v.24, n.10, p.1561-1573, 2001.

FLOWERS, T. J. Improving crop salt tolerance. Journal of Experimental Botany, v. 55, n. 396, p. 307-319, 2004.

LABORIAL, L. G.; VALADARES, M. B.On the germination of seeds of Calotropisprocera.Anais da Academia Brasileira de Ciências, São Paulo, v.48, p.174-186, 1976.

LACERDA, C.F.; CAMBRAIA, J.; OLIVA, M.A.; RUIZ, H.A.; PRISCO, J.T. Solute accumulation and distributions during shoot and development in two 


\section{USO DE ÁGUAS SALINAS E ADUBAÇÃO NITROGENADA NO CULTIVO DA MAMONEIRA BRS-ENERGIA}

sorghum genotypes under salt stress. Environmental and Experimental of Botany,v.49, n.1, p.107-120, 2003.

LARCHER W. EcofisiologiaVegetal. São Carlos: Rima, 2004. 531 p.

LIMA C. B.; SANTOS FILHO, S. V. dos; SANTOS, M. A. dos; OLIVEIRA, M. de . Desenvolvimento da mamoneira, cultivada em vasos, sob diferentes níveis de salinidade da água em Latossolo Vermelho-amarelo eutrófico. Revista Caatinga,v.21, n.5, p.50-56, 2008.

LIMA, G. S. de; SOARES, L. A. dos A.; NOBRE, R. G.; GHEYI, H. R.; SILVA, A. O. da. Crescimento inicial da mamoneira sob diferentes salinidades da água de irrigação e doses de nitrogênio. Revista Verde de Agroecologia e Agricultura Sustentável, v.6, n.2, p.201-209, 2011a.

LIMA, G. S. de; SOARES, L. A. dos A.; NOBRE, R. G.; GHEYI, H. R.; SILVA, S. S. da. Influência do estresse salino e da adubação nitrogenada no crescimento da mamoneira cv. BRS-Energia. Revista Verde de Agroecologia e Agricultura Sustentável,v.6, n.3, p.213-221, 2011 b.

MAGUIRE, J.D. Speed of germination aid in selection and evaluation for seedling emergence and vigor. Crop Science, Madison, v.2, n.2, p.176-177, 1962.

MEDEIROS, J. F. de; SILVA, M. C. C.; SARMENTO, D. H. A.; BARROS, A. D. de. Crescimento do meloeiro cultivado sob diferentes níveis de salinidade, com e sem cobertura do solo. Revista Brasileira de Engenharia Agrícola e Ambiental,v.11, p.248-255, 2007.

MENGUEL, K.; KIRKBY, E.A. Principlesofplantnutrition. 4 ed.Bern: International Potash Institute, 1987. 687p.
MILANI, M. BRS Energia. 3 ed. Campina Grande - PB:Embrapa Algodão, 2010. (Folder).

NERY, A. R.; SILVA, M. B. R.; RODRIGUES, L. N.; FERNANDES, P. D.; DANTAS NETO, J.; VIEGAS, R. A. Taxas de crescimento do pinhão manso cultivado com água de diferentes níveis de salinidade. In: WORKSHOP MANEJO E CONTROLE DA SALINIDADE NA AGRICULTURA IRRIGADA, 2007. Recife. Anais... Recife-PE: UFRPE/UFCG. 2007. 4 p.

NEUMANN P. Salinity resistance and plant growth revisited. Plant Cell and Environment, v.20, p.1193-1198, 1997.

NOVAIS R. F.; NEVES J. C. L.; BARROS N. F. Ensaio em ambiente controlado. In: OLIVEIRA A. J. Métodos de pesquisa em fertilidade do solo. Brasília: Embrapa-SEA. p. 189-253. 1991.

PIZARRO, F. Drenaje agrícola y recuperacion de suelos salinos.Madrid: Editora Agrícola Española, S.A., 1985. $542 p$.

RHOADES, J.D.; LOVEDAY, J.G. Salinity in irrigated agriculture.In: Stewart, D.R.; Nielsen, D.R. (ed.) Irrigaton of agriculturalcrops. Madison: ASA, CSSA, SSSA, 1990. p.1089-1142. Agronomy, 30

RICHARDS, L. A. Diagnosis and improvement of saline and alkali soils, Washington: U.S, Department of Agriculture, 1954.160p

SILVA, E.C.; NOGUEIRA, R.J.M.C.; ARAUJO, F.P.; MELO, N.F.; AZEVEDO NETO, A.D.; Physiological responses to salt stress in young umbu plants. 

BRS-ENERGIA

Environmental and Experimental

Botany, v.63, n.1-3, p.147-157, 2008.

SILVA, S. M. S.; ALVES, A. N.; GHEYI, H. R.; BELTRÃO, N. E. DE M.; SEVERINO, L. S.; SOARES, F. A. L. Germinação e crescimento inicial de duas cultivares de mamoneira sob estresse salino. Revista Brasileira de Engenharia Agrícola e Ambiental,v.9, (Suplemento), p.347-352, 2005.

SILVA, S. M. S.; ALVES, A. N.; GHEYI, H. R.; BELTRÃO, N. E. de M.; SEVERINO, L. S.; SOARES, F. A. L. Desenvolvimento e produção de duas cultivares de mamoneira sob estresse salino. Revista Brasileira de Engenharia Agrícola e Ambiental,v. 12, n. 4, p. 335342, 2008a.

SOUSA, A. E. C.; GHEYI, H. R.; CORREIA, K. G.; SOARES, F. A. L.; NOBRE, R. G. Crescimento e cosumo hídrico do pinhão manso sob estresse salino e doses de fósforo. Revista Ciência Agronômica, v. 42, n. 2, p. 310-318, 2011.

TAIZ, L.; ZEIGER, E. Fisiologia vegetal. 3.ed. Porto Alegre: Artmed, 2009. 719p.

Tester, M., Davenport, R. $\mathrm{Na}^{+}$tolerance and $\mathrm{Na}^{+}$transport in higher plants. Annals of Botany, v.91, p.503-527, 2003. 